\title{
ANTECEDENTES COLONIZADORES EN LA ESPAÑA DEL SIGLO XVIII. PROYECTOS Y REALIDADES EN LAS TIERRAS DE LA ANTIGUA CORONA DE ARAGÓN*
}

\author{
ARMANDO ALBEROLA ROMÁ \\ y ENRIQUE GIMÉNEZ LÓPEZ
}

Universidad de Alicante

\section{RESUMEN}

El interés del reformismo borbónico por la colonización interior dio lugar, en los territorios de la antigua Corona de Aragón, a multitud de iniciativas que, en la segunda mitad del siglo XVIII, contaron con el modelo repoblador de Sierra Morena y, desde 1772, con la reposición del Fuero Alfonsino de 1329, privilegio que permitía obtener la jurisdicción baronal. Es por ello que junto a consideraciones poblacionistas sea frecuente encontrar en estos proyectos motivaciones especulativas o un medio para ingresar en el estamento privilegiado.

\section{ABSTRACT}

The interest of the Borbonic reforming policy about the interior colonization granted -in the ancient Aragon's Crown lands- many enterprises which, on the second half of the $18^{\text {th }}$ Century, counted with the model of repopulation of Sierra Morena and, from 1772, with the replacement of the Fuero Alfonsino of 1329, a privilege that allowed to get the baronal jurisdiction. That is the way, togheter with repopulation thoughts, it was easy to find, in these proyects, speculative motivations or a way to get into the privileged class.

Una de las iniciativas del reformismo ilustrado que más se tiende a destacar es el denominado «experimento» de las Nuevas Poblaciones de Sierra

* El presente artículo tiene su base en la ponencia presentada en el curso organizado en mayo de 1995 por la Universidad Internacional Menéndez Pelayo (sede Valencia) bajo el título La colonización en España. 
Morena. Empresa estrechamente vinculada a la resolución de los problemas demográficos y agrarios de la España del último tercio del siglo XVIII, generó amplias expectativas y una legislación específica convenientemente recogida en la Novísima Recopilación.

A lo largo de la centuria diferentes pensadores reflexionaron acerca de las razones que explicaran la despoblación perceptible en amplias áreas peninsulares; reflexión vinculada, por otro lado, al problema general de los modestos recursos demográficos con que contaba el país. A los factores ya conocidos como causantes de este mal - guerras, emigración al Nuevo Mundo, elevado número de religiosos - comenzaron a añadirse los de tenor esencialmente económico, de entre los que la desigual distribución de la tierra se revelaba como elemento clave. De ahi que una reforma agraria de amplio alcance resultara ser una posible solución a este mal que aquejaba al país.

El plan de colonizar las tierras desiertas situadas a lo largo del camino real que desde Madrid se dirigía a Andalucía perseguía un objetivo doble: demográfico y social. La idea no era nueva, pues anteriores proyectistas habían lanzado la propuesta de traer a España colonos católicos procedentes de otros países europeos. Sin embargo el ambiente que se vivía en la década de los sesenta del siglo XVIII resultó propicio para que el plan, de la mano del intendente Olavide, arrancara con decisión.

Desde el punto de vista de la estricta repoblación o colonización interior, el experimento resultó exitoso tal y como lo prueban los núcleos urbanos fundados y el hecho de que ampliara su inicial radio de acción alcanzando, desde Sierra Morena, la campiña cordobesa y las tierras sevillanas. Contemplado desde la óptica de la reforma agraria el experimento se reveló incapaz de transformar la realidad social del campo andaluz. No obstante la iniciativa serviría de modelo en otros lugares de la geografía peninsular, aunque también cabe decir que combinada con otras posibilidades legales, de entre las que la reposición del privilegio alfonsino fue la más socorrida.

Junto a ello también se deben indicar una serie de propuestas, proyectos y realizaciones que, con un claro objetivo colonizador, se plantearon e, incluso, se llevaron a cabo durante la primera mitad del siglo XVIII. Y es que la percepción de que el número de vasallos con que contaba la nueva dinastía borbónica era menguado despertó un temprano interés y un evidente deseo de hallar soluciones.

Pongamos un ejemplo. El 10 de mayo del año 1729 remitía a Felipe V don Francisco Marcos de Molina, caballero de la Orden de Santiago, un es- 
cueto Memorial en el que, tras considerar que el poderío de las naciones descansaba en el número de sus súbditos más que en la extensión de sus territorios, proponía incrementar los exigüos contingentes demográficos del país - que cifraba en tan sólo cuatro millones- en dos mil vecinos cada año '. Tal propuesta no la efectuaba de manera altruista, ya que solicitaba una serie de compensaciones de entre las que destacaban el nombramiento de comisario general del Aumento de Población y Vecindario o la concesión, para él y sus sucesores, de la «jurisdicción, señorío y vasallaje» de todas las nuevas poblaciones, en ningún caso inferiores a treinta vecinos, que pudieran construir en los despoblados realengos. Además reclamaba a la Corona los caudales necesarios para emprender la empresa y se permitía el lujo de urgir al rey en su respuesta; pues a su entender no podía exceder de un mes a partir de la recepción del escrito ${ }^{2}$.

Con estos condicionantes no debe resultar, por tanto, extraño que tras la correspondiente - y rápida - consulta del marqués de la Compuesta al gobernador del Consejo de Castilla ${ }^{3}$ el proyecto fuera seriamente cuestionado y, a la postre, desestimado. Los argumentos esgrimidos fueron de diversa índole, aunque sobre todo se criticaba su falta de concreción a la hora de establecer la procedencia de los hipotéticos dos mil pobladores anuales, la ausencia de una metodología para su traslado y establecimiento así como un excesivo interés personal del tal Molina, toscamente enmascarado en su proposición, por medrar y enriquecerse ${ }^{4}$.

Sin embargo este «Proyecto de Población»-puesto que de esta guisa era calificado por el gobernador del Consejo de Castilla- enlaza directamente, en su fondo y forma, con las propuestas efectuadas en el siglo anterior por los denominados arbitristas ${ }^{5}$. Éstos ya mostraron su preocupación por el gran vacío poblacional existente en el país influyendo sus textos, sin ningún género de duda, en el pensamiento de los ilustrados ${ }^{6}$. Por ello no re-

${ }^{1}$ Archivo General de Simancas (A.G.S.), Gracia y Justicia, leg. 481, Memorial de D. Francisco Marcos de Molina; Madrid, 10-5-1729.

2 «Sin que me obligue a lo ofrecido pasada la demora de un mes; por la experiencia que hay de haverse desvanezido las mas importantes exposiciones en la morosidad de la Resolución», ibidem.

${ }^{3}$ A.G.S., Gracia y Justicia, leg. 841, El marqués de la Compuesta al Arzobispo de Valencia; Palacio, 29-5-1729.

4 A.G.S., Gracia y Justicia, leg. 841, Andrés, Arzobispo de Valencia, Gobernador del Consejo; Madrid, 2-7-1729.

'Sobre los términos proyecto y proyectismo, ver el breve, pero interesante, trabajo de Álvarez de Miranda (1986), pp. 133-150. Acerca de los arbitristas, ver el ya clásico estudio de Vilar (1973).

\footnotetext{
${ }^{6}$ Martín Rodríguez (1984).
} 
sulta en absoluto extraño que las reflexiones de Saavedra Fajardo o de Martínez de la Mata ${ }^{7}$, enunciadas en las décadas centrales del Seiscientos, fueran citadas o tomadas en consideración, en buena medida, por teóricos setecentistas como Gerónimo Uztáriz, Bernardo de Ulloa, Fray Alejandro Aguado o Campomanes que, de este modo, se convertían en herederos de la tradición poblacionista de aquéllos ${ }^{8}$. Para Jordi Nadal el pensamiento demográfico del XVIII español quedaría compendiado en estas frases de Antonio de Capmany:

La población de un país es una de las reglas más sencillas para juzgar de la bondad de su constitución. Quando la despoblación crece, el Estado camina a su ruina; y el país que aumenta su población, aunque sea el más pobre, es ciertamente el mejor gobernado?.

Correspondió, por tanto, al reformismo borbónico de la segunda mitad del siglo XVIII la instrumentación de una auténtica política de colonización interior, la cual se incluiría en el marco de un ambicioso programa de recuperación económica del país al que, no obstante, cabe reprocharle que en ningún momento llegara a cuestionar el sistema social imperante. De todos modos, aquí radica la gran diferencia con el arbitrismo que impulsó a los gobernantes del último cuarto del siglo XVI y la primera mitad del XVII a promulgar disposiciones legales tendentes a sanear no sólo la moral o las costumbres, sino la propia situación del agro español. Sin embargo las medidas que, en este caso y para tal fin, se adoptaron no pueden ser consideradas como parte de un auténtico programa ya que se referían a aspectos sectoriales de la actividad agraria ${ }^{10}$.

En el siglo XVII, y pese al cambio sustancial de planteamientos, no se puede hablar de despliegue de una auténtica política agraria, en el sentido más amplio del término, hasta el reinado de Carlos III. Sería a partir de la década de los sesenta cuando, merced al impulso de los ministros ilustrados, se comenzaría a configurar un corpus legislativo que vendria a sustituir a las

7 «La fuerza de los reinos consiste en el número de vasallos. Quien tiene más es mayor príncipe, no el que tiene más estados, porque estos no se defienden por sí mismos sino por sus habitadores.» «A la multitud acompañan los frutos, proporcionándose la abundancia como la sombra al cuerpo. Si sobra multitud y falta lo necesario de frutos, padece la multitud. Si sobran frutos y falta multitud que los ha de consumir, se pierden los frutos.» Ver, respectivamente: Saavedra Fajardo (1947), Anes (1971).

8 Giménez López (1993).

${ }^{9}$ Nadal Oller (1976).

10 García Sanz (1989), pp. 629-638. 
medidas que ocasionalmente se habían tomado con anterioridad en momentos de crisis. Aún más, en este período la iniciativa institucional con «fines múltiples y ambiciosos aunque no siempre coherentes», al decir de Domínguez Ortiz ", se convertiría en el motor de la reforma suplantando de manera ya casi definitiva a las iniciativas privadas.

Cuando se habla de colonización se tiende, invariablemente, a acotar temática y cronológicamente el significado del término. De ahí que las referencias usuales conduzcan, como punto de partida, a la Real Cédula de 5 de julio de 1767 que contiene la Instrucción y Fuero de Población para las tierras de Sierra Morena y Andalucía o a la instrucción, en 1768, del Expediente General de Despoblados del Reino ${ }^{12}$. Ello suele dejar, por tanto, fuera de lugar a una serie de iniciativas y actuaciones de gran interés que tuvieron como marco la primera mitad de la centuria - aunque algunas sobrepasarían incluso este límite-, y como objetivo el saneamiento de áreas deprimidas y encharcadas con el fin de incrementar la superficie cultivable, conjurar los problemas sanitarios que indefectiblemente provocaban un elevado número de víctimas al año y, en última instancia, favorecer el asentamiento de nuevos contingentes de población.

El presente estudio pretende, en consecuencia, aludir a esos antecedentes colonizadores de diversa índole que culminarian con el ambicioso proyecto de las Nuevas Poblaciones y, además, a las consecuencias - traducidas en esos nuevos enclaves- que de la aplicación de la legislación emanada para hacerlo posible se pueden observar fundamentalmente en las tierras valencianas y, por extensión, en el ámbito de la antigua Corona de Aragón.

\section{LA COLONIZACIÓN DURANTE EL PRERREFORMISMO}

Estima Braudel que la colonización de las tierras bajas para vaciarlas de aguas malsanas, dotarlas de riego y surcarlas de caminos ha sido el rasgo verdadero y original de la historia rural del hombre del Mediterráneo ${ }^{13}$. La desecación perseguia, además, acabar con las fiebres tercianas que, indefecti-

11 Domínguez Ortiz (1976), pág. 418.

12 Dominguez Ortiz (1976), pp. 445-446.

13 Braudel (1976, 2." ed.), vol. I, pág. 84. 
blemente, aparecían en estos lugares tan pronto apretaban los calores estivales y proliferaban los mosquitos. Y ello porque el paludismo se vincula tanto a la expansión de los cultivos arroceros como a la proliferación de áreas pantanosas y encharcadas. Durante el siglo XVIII éstas eran ciertamente abundantes en el territorio valenciano, junto con las lagunas litorales e interiores. Por otro lado, la ampliación de las tierras dedicadas a la explotación arrocera es un hito suficientemente conocido a pesar de las trabas legales que, con antecedentes en la época medieval, intentaron limitar su crecimiento durante el Setecientos ${ }^{14}$. Si el arroz favoreció el incremento de la población valenciana durante este siglo procurando su alimentación en los momentos difíciles derivados de las habituales carencias trigueras, es bien cierto que lo hizo a costa de causar la enfermedad y, en muchas ocasiones, la muerte de sus cultivadores ${ }^{15}$.

Dadas las especiales características del solar valenciano esta práctica desecadora, generalizada por otro lado en toda la cuenca mediterránea, ha llegado a ser considerada como un fenómeno genuino del mismo por la profusión con que fue empleada a lo largo de la historia ${ }^{16}$. Constituyen ejemplos paradigmáticos de ésta, entre otros, la ingente obra desarrollada por el cardenal Belluga en el Bajo Segura en las primeras décadas del siglo XVIII en las denominadas Pías Fundaciones, la colmatación masiva de parcelas en la Albufera valenciana o los intentos llevados a cabo, con mayor o menor fortuna, en Salinas, Bassa Llarguera y Almarjales de Elche y la laguna de Villena.

A partir de 1715 don Luis Belluga y Moncada, obispo proborbónico de Cartagena, inició las gestiones para obtener, con el propósito de desecarla posteriormente, una amplia superficie de almarjal ${ }^{17}$ cercana a las 40.000 tahúllas —algo más de $44.000 \mathrm{~m}^{2}$ - localizada entre la vega oriolana y el término de Elche ${ }^{18}$. Para Millán y García-Varela este hecho viene a representar la culminación de un largo proceso colonizador y de asentamiento iniciado en la centuria anterior, del que el fracaso en la creación de un se-

${ }_{14}$ Peset, M. y J. L. (1972a), pp. 277-375. De los mismos autores (1972b).

15 Mateu (1987), pp. 77-78.

16 Ardit Lucas (1977), p. 25.

17 Rafael Altamira indica que Belluga obtuvo en 1715 de la ciudad de Orihuela la donación de 25.000 tahúllas bajo ciertas condiciones. Cinco años más tarde Guardamar hizo lo propio con otras 13.000 , logrando del monarca en agosto de 1725 la cesión de $222 \mathrm{Ha}$ en el realengo denominado de la Majada Vieja. Cifr. en Altamira y Crevea (1905), p. 140.

${ }^{18}$ León Closa (1962-1963), reimpr. en Cremades Griñán (1985), pp. 221-268. Ver, además, Millán y García Varela (1984), pp. 176 y ss.; Gil Olcina y Canales Martínez (1988), pp. 80-82; Cremades Griñán (1991), pp. 363-380; Gil Olcina (1992), pp. 146-148. 
ñorío alfonsino en Catral por parte de don Ginés Juan Portillo en 1691 o el ensayo del ayuntamiento oriolano, segado de raíz por la Guerra de Sucesión, de colonizar parcialmente unas 4.500 tahúllas serían sus referentes más próximos.

Hacia 1730 comenzaron a llegar los primeros colonos para ocupar las tierras que deseaba colmatar Belluga, consiguiendo poner en producción algo más de 15.000 tahúllas catorce años más tarde. En 1730 se fundaron, asimismo, las poblaciones de San Fulgencio, en el extremo más oriental; San Felipe Neri, próximo al saladar de Albatera, y de Nuestra Señora de los Dolores, en el centro. En el año 1734 estas poblaciones alcanzarían la condición de villas. La escritura fundacional, otorgada por Belluga - ya cardenal- en Roma el 18 de septiembre de 1741 y aprobada por Real Cédula de 20 de febrero de 1742, detallaba en 35 capítulos las condiciones bajo las que se establecieron los labradores en las tierras hasta entonces de almarjal. Éstos las recibieron en régimen de enfiteusis, debiendo abonar un canon en especie fijado en principio en la cuarta parte de todas las cosechas que, en el año 1745 , fue suavizado hasta la sexta parte.

Cuando en 1715 Belluga obtuvo de Orihuela las 25.000 tahúllas con que inició el proceso de creación de las posteriormente conocidas como Pías Fundaciones, fue bajo la condición de que habría de trazar un canal de desagüe que vertiera las aguas en término de Elche, cosa a la que en principio se opuso el duque de Arcos y marqués de Elche. No obstante en 1721 permitió la construcción del azarbe para obtener de Fernando VI, en 1748, la concesión de una serie de exenciones por espacio de veinte años para todos aquellos que estuvieran dispuestos a desecar las tierras de los Carrizales próximos a la laguna de Bassa Llarguera y a asentarse en San Francisco de Asís, población de nueva planta que se alzaría en la sierra del Molar ${ }^{19}$. Al igual que en las Fundaciones de Belluga fue la enfiteusis el contrato agrario empleado, obligándose los colonos a roturar las tierras establecidas antes de tres años así como a la entrega de la sexta parte de los frutos cosechados, excepto la barrilla que ascendía a la cuarta parte. El marqués de Elche, además, permitía la edificación de casas y la construcción de artefactos para elevar aguas muertas, aunque prohibía la siembra de plantas barrilleras de no mediar su expreso consentimiento.

La empresa conoció muchas dificultades, viéndose obligado el marqués a solicitar de la Corona en los años 1768 y 1781 prórrogas en la exención de

19 Altamira y Crevea (1905), pp. 120-124. Gozálvez Pérez (1977), pp. 48 y ss. Ruiz Torres (1981), pp. 110-114 y 190-ss. Box Amorós (1987), pp. 209-243. 
los impuestos pues, tan sólo en el período 1780-1784, había tenido que afrontar un gasto de casi 120.000 dineros generado por la construcción y conservación de azarbes. En las postrimerías de la centuria aún quedaba por bonificar más de la mitad del terreno, caracterizándose los enfiteutas por su absentismo. Éste y el permanente azote de las fiebres tercianas acabaron con la nueva población de San Francisco de Asís ${ }^{20}$.

Iniciativas similares tendentes a lograr el asentamiento estable de vecinos en enclaves despoblados, aunque con fracasos más sonoros, tuvieron lugar en otras áreas de la geografía hispana. Así, en 1720, el coronel Bartolomé Porro solicitó permiso, y lo obtuvo, para poblar con naturales del Finale (ducado de Parma) las tierras baldías y desérticas comprendidas entre Tarifa y Algeciras, a la vez que establecer diferentes fábricas de papel y lencería ${ }^{21}$. Como compensación logró el grado de mariscal de campo, con un sueldo de 500 escudos mensuales, así como la jurisdicción militar perpetua en Algeciras, de la que fue privado el marqués de Pozoblanco, su titular hasta esas fechas. Bastaron dos años para comprobar que Porro tenía un carácter agrio y despótico y que su proyecto no pasaba de ser una fantasía. Un informe del Consejo de Castilla denunciaba

el ningún fundamento ni esperanza que se puede tener de la Población que tomó a su cargo, concluyendo que las de Bolonia y Valdevaqueros que ha dado a entender que principiaba son de ninguna substancia ni utilidad, ni pueden serlo para su Magd. y la causa publica, y que solo se descubre en lo executado por Porro una idea fantastica, suponiendo poder facilitar y fundar los Pueblos que no pueden subsistir, ni tener efecto, ni se halla con disposiciones; ni mas finalinos que un criado suyo, y lo demas trabajadores aparentes españoles, portugueses y un pequeño resto de 25 hombres de todas naciones, genoveses, florentines, palanquines y esportilleros que ha llevado de Cádiz, de los que dice andan rodando, y algunos vagamundos a quienes injustamente da el nombre de finalinos; y reconoce ser su animo doloso y solo utilizarse, como lo ha hecho, en notorio perjuicio de la Rl. Hazda. y vasallos de su Magd ${ }^{22}$.

Ante tal cúmulo de méritos fue puesto preso a fines de enero de 1723 en el castillo de Santa Catalina de Cádiz, para su posterior proceso, concluyendo, de este modo, el proyecto que tanto interés había despertado tan sólo tres años atrás.

20 AGS., Gracia y Justicia, leg. 845; Guerra Moderna, leg. 3485.

${ }^{21}$ Giménez López (1993), p. 142.

22 AGS., Gracia y Justicia, leg. 89. 
A principios de la década de los cuarenta se pretendió colonizar las sierras de Requena y Barciles, y a fines de la misma el coronel Wettstein proponía al marqués del Puerto, embajador español en Holanda, situar en despoblados españoles a millar y medio de familias católicas procedentes de Flandes que penetrarían en el país por los puertos de Bilbao y San Sebastián. En 1750 los jerónimos del convento cordobés de Valparaíso pretendían roturar baldíos comunales y construir una nueva población en Espiel, cosa que no lograron ${ }^{23}$.

Pero volvamos al tema de la desecación de áreas pantanosas en territorio valenciano. El botánico Cavanilles, en la obra que recoge las valiosas anotaciones realizadas durante su recorrido por el antiguo reino a fines del siglo XVIII, refiere con detalle estos enclaves insalubres a la vez que pone de relieve las desgracias que asolaban a quienes habitaban en sus proximidades. Gracias a él sabemos de municipios tan deprimidos como Museros o Solla$\mathrm{na}^{24}$, así como de los inconvenientes padecidos por los vecinos de Oropesa o Torreblanca, sometidos al embate periódico y sistemático de las fiebres como consecuencia de su cercanía a las albuferas de idéntico nombre ${ }^{25}$. Las soluciones apuntadas por el ilustrado valenciano entran de lleno en la dinámica económico-sanitaria propia del Setecientos, habiéndose llevado a la práctica algunas de ellas a lo largo de la centuria. El desagüe de las lagunas interiores y la bonificación de los almarjales y albuferas costeros perseguían conjugar los beneficios económicos derivados de la ampliación de la superficie cultivable y la mejora del hábitat, al conseguir acabar con los problemas de insalubridad. El destierro de las fiebres tercianas iba unido, indefectiblemente, a la explotación exhaustiva de los fondos de las lagunas $\mathrm{y}$ al aprovechamiento para riego de las aguas evacuadas.

La denominada Albufereta de Alicante, pequeña laguna litoral situada al norte de la ciudad y permanente foco de paludismo, conoció un proceso progresivo de colmatación que se extendió desde fines de 1677 hasta prácticamente nuestros días ${ }^{26}$. No obstante el mayor impulso se produjo durante el siglo XVIII cuando el municipio decidió afrontar los gastos que tal empresa comportaba. Pese a que la Guerra de Sucesión interrumpió unos trabajos iniciados en 1704, los intentos llevados a cabo en los años veinte consiguieron sanear una importante porción de laguna. Fue en las postri-

23 Sambricio (1991), pp. 120-121; Gómez Crespo (1968), pp. 237-250.

${ }_{24}$ Cavanilles (1795-1797), vol. I, respectivamente pp. 129-131 y 189.

25 Cavanilles (1795-1797), vol. I, pp. 48-49.

26 Alberola Romá (1989), pp. 69-81. 
merías de la centuria cuando tres influyentes ciudadanos alicantinos solicitaron de la Intendencia valenciana la concesión en enfiteusis de los 129 jornales de almarjal de que constaba la laguna con el fin de sanearlos y ponerlos en producción. En 1790 obtuvieron el dominio útil de dicha superficie por el módico canon anual de seis dineros por cahizada, aunque ello no significó el fin del proceso de bonificación, que se alargaría hasta el año 1928.

La laguna de Salinas conoció también tentativas para su desagüe y bonificación. Cavanilles le dedica especial atención por lo peligrosa que resultaba para la salud de la cercana localidad de idéntico nombre, pues hubo años en que las tercianas llegaron a reducir el número de habitantes en dos terceras partes; sin olvidar que un excesivo crecimiento del nivel de sus aguas en 1752 motivó el traslado de la población a lugar más seguro ${ }^{27}$. A fines del siglo XVIII un particular llamado Francisco Sirera pretendió la evacuación de sus aguas hacia el río Vinalopó mediante la apertura de una mina de 23.000 palmos de largo. Su propósito no alcanzó el éxito deseado, pues en 1801 Esteban Chaix presentaba un nuevo proyecto de desecación, esta vez por la parte sur, aunque su elevado coste, que había de ser asumido por los interesados, condujo a un nuevo fracaso. Hubo otras tentativas durante el XIX, pero la desecación efectiva de la laguna de Salinas no se consiguió hasta el presente siglo ${ }^{28}$.

En 1760 la villa de Elche, deseosa de paliar su habitual déficit en caudales para riego, propuso a la de Villena la desecación de su laguna. Ésta aceptó porque, sobrada de aguas con que atender su regadío, la propuesta significaba alejar de una manera definitiva el fantasma de las fiebres. Sin embargo el abierto rechazo por parte de Sax, Elda y Novelda, tradicionalmente enfrentadas a Elche por los sobrantes de Villena, provocó la suspensión de la empresa. Idéntico destino conocieron las iniciativas de 1764 y 1770. Sin embargo en 1785 fue la Secretaría de Hacienda la que tramitó un nuevo informe relativo al desagüe y desecación de la laguna de Villena que a punto estuvo de llegar a buen fin. Hubo que esperar, no obstante, hasta 1803 para que se produjera el inicio de las obras dirigidas por Juan de Villanueva, arquitecto mayor de Carlos IV. El coste total alcanzó 1.444 .496 reales, acotando los funcionarios reales tras la desecación una superficie en torno a la laguna de algo más de 17.200 tahúllas cuya administración pasó a ejercer la Real Hacienda. Ésta se reservó para sí el dominio directo de

27 Cavanilles (1795-1797), vol. II, pp. 260-261.

28 Arroyo Ilera (1976), pp. 34-37. Amat (1875), ff. 179-196. Box Amorós (1987), pp. 52-89. 
aquélla, aunque concedió el útil a algunos labradores que pasaron a ser conocidos con el nombre de «laguneros» ${ }^{29}$.

En las comarcas centrales valencianas el fenómeno más destacado de colmatación masiva de un área encharcada se produjo en la Albufera de Valencia, perfectamente estudiado por Carmen García Monerris ${ }^{30}$. A lo largo de la centuria fueron bonificadas más de 3.300 hectáreas merced al empuje de un colectivo de interesados de composición muy heterogénea, aunque dotado de considerable pragmatismo y criterios inversionistas. En el último cuarto del siglo XVIII también serían en buena medida desecados, gracias a la autorización del duque de Gandía, los almarjales de Xeraco y Xeresa ${ }^{31}$. En la lejana Galicia, y casi en paralelo con el inicio de la desecación de la Albufera, un proyecto de Carlos Lemaur proponía hacer lo propio con los juncales de Betanzos; impidiendo la oposición de la ciudad que aquél prosperara ${ }^{32}$.

\section{LA CORONA Y LOS INSTRUMENTOS LEGALES PARA LA COLONIZACIÓN INTERIOR EN LA SEGUNDA MITAD DEL SIGLO XVIII: EL FUERO DE POBLACIÓN DE SIERRA MORENA (1767) Y LA REPOSICIÓN DEL FUERO ALFONSINO (1772)}

El proyecto más ambicioso trazado por los políticos agraristas del siglo ilustrado español lo constituyó, sin duda, la colonización de una amplia zona de Sierra Morena y Andalucía ${ }^{33}$. Conocido como las Nuevas Poblaciones, su soporte legal se halla en las Reglas para las nuevas poblaciones de Sierra Morena y Fuero de sus pobladores, contenidas en la Real Cédula de 5 de julio de $1767^{34}$, y supone la síntesis del poblacionismo y una auténtica guía para las empresas colonizadoras impulsadas por la Corona en la segunda mitad del siglo XVIII.

Como indicábamos páginas atrás, el excesivo, y lógico por otra parte, protagonismo otorgado a esta Real Cédula ha propiciado que los historia-

29 Amat (1875), ff. 58-75. García Martínez (1964), pp. 179-203. Hernández Marco (1983)

Gil Olcina (1984). Box Amorós (1987), pp. 89-115.

${ }^{30}$ García Monerris (1985).

31 Morant Deusa (1984).

32 Sambricio (1991), p. 126.

33 La bibliografia sobre esta cuestión es ya muy extensa, por lo que remitimos a Avilés Fernández (1991), pp. 13-32.

${ }^{34}$ Novisima Recopilación, libro VII, título XXII, ley III. 
dores desviaran su atención del Privilegio concedido por Alfonso IV de Aragón en las Cortes valencianas del año 1329, incurso en el decreto abolicionista de los Fueros valencianos de 1707 y repuesto, como eficaz instrumento colonizador, por Carlos III en 1772. Dicho privilegio otorgaba la jurisdicción criminal baja y la civil plena a quienes, no teniendo el mero imperio, acreditaran la fundación o la posesión del dominio directo de un lugar en el que, como mínimo, existieran quince casas de cristianos viejos. Este privilegio, incorporado a los Fueros valencianos, potenció la recolonización interior del reino, permitió ejercer funciones de control y policía a los señores alfonsinos y, sobre todo, propició una mayor cohesión política ${ }^{35}$.

La abolición de los Fueros valencianos el 29 de junio de 1707 planteó una duda referida a si el privilegio alfonsino quedaba incluido en el decreto abolicionista o si, por contra, su vigencia resultaba plena y, en consecuencia, podía recurrirse al mismo a la hora de fundar nuevos lugares y reclamar su jurisdicción. Un Decreto expedido en idéntica fecha, tendente a tranquilizar a los «buenos vasallos», y una resolución del Consejo de Castilla de 5 de noviembre de 1708 parecian respetar la vigencia del privilegio alfonsino. Hace años ya apuntamos, tras una lectura atenta de las disposiciones legales, que el Fuero Alfonsino quedó incurso en el decreto abolicionista. Ello significó, sin embargo, el respeto a las jurisdicciones alfonsinas ya existentes hasta la fecha, aunque dejara en suspenso la posibilidad de obtenerlas a partir de ese momento al amparo del viejo fuero de $1329^{36}$. Estudios más recientes y documentados han venido a confirmar aquella interpretación ${ }^{37}$.

Una Real Provisión de 16 de mayo de 1772 repuso el fuero alfonsino en el antiguo reino valenciano ${ }^{38}$. Carlos III dispondría años más tarde en el artículo sexto de las Reglas para la construcción de poblaciones en el camino entre Madrid y Extremadura que, si llegaban a veinte vecinos, podían disfrutar de la jurisdicción alfonsina «para que se puedan defender de toda vexación» ${ }^{39}$. Por ello la obligada referencia al Fuero de Población de Sierra Morena ha de verse compartida con el Fuero Alfonsino cuya pervivencia, no olvidemos, fue incluso defendido por don Melchor de Macanaz en plena vorágine abolicionista de primeros de siglo ${ }^{40}$.

35 Para un estudio muy pormenorizado, ver Pla Alberola (1993), pp. 79-140.

${ }^{36}$ Alberola Romá (1984), p. 419. Del mismo autor (1993), vol. I, pp. 223-240.

${ }_{37}$ Pla Alberola (1993), pp. 99-100. Giménez López (1993), pp. 144-145.

${ }_{38}$ Novísima Recopilación. Suplemento, libro III, título III, ley I. Pla Alberola (1993), pp. 104 y ss.

39 Novísima Recopilación, libro III, título IV, ley VI.

${ }^{40}$ Pla Alberola (1993), pp. 99-100. 


\subsection{La utilización del Fuero Alfonsino en la repoblación de la Corona de Aragón}

Merced a la aplicación de este privilegio se cursaron numerosas solicitudes y fueron creadas en tierras valencianas varias poblaciones, a cuyos titulares se les concedió la baja jurisdicción. Un somero inventario arrojaría el balance que recoge el cuadro adjunto.

\section{CUADRO 1}

Poblaciones establecidas en tierras valencianas en aplicación del privilegio alfonsino (1773-1798)

\begin{tabular}{ll}
\hline Año & \multicolumn{1}{c}{ Población } \\
\hline 1773 & San Rafael \\
1774 & La Sarga \\
1778 & Venta del Emperador \\
1779 & La Vallonga* \\
1787 & Santa Maria de Aguas Vivas \\
1788 & Peñacerrada \\
1789 & Benadressa** \\
1791 & Daya Vieja \\
1798 & Algorfa \\
\hline
\end{tabular}

* Solicitud no concedida.

** Solicitud concedida aunque no hecha efectiva.

El privilegio fue invocado, en ocasiones combinado con el de Sierra Morena, para intentar establecer nuevas poblaciones en otros lugares. Así sucede en el caso de la solicitud de Dionisio Areny, un militar que era gobernador de una fortificación costera -el fuerte de San Jorge- situada en el corregimiento de Tortosa, y titular del dominio útil de un territorio despoblado situado entre la villa de Tivisa y la costa por donde discurría el camino real que unía Valencia con Barcelona. En 1768, Areny pretendió fundar en aquel lugar una nueva población de 20 casas, utilizando algunos capítulos de la cédula que regulaba la repoblación de Sierra Morena. A cambio de su esfuerzo repoblador solicitaba, entre otras gracias, la obtención de la jurisdicción civil y criminal ${ }^{41}$. El dictamen elaborado por el fiscal

${ }^{41}$ A.H.N., Consejos, Libro 1.939, ff. 1-12v. 
del Consejo de Castilla sobre la petición de Areny hacía una interesante referencia a la jurisdicción alfonsina que, en su opinión, debía ser la que se otorgara como gracia a Areny en lugar de la suprema civil y criminal solicitada por éste, lo que parece indicar que, si bien la utilización del privilegio alfonsino como vía repobladora se cerró para Valencia tras el Decreto abolicionista de junio de 1707, quedó abierta para los territorios de Tortosa, un ámbito geográfico escasamente poblado, dada la situación excepcional que conoció Tortosa entre 1708 y 1714, período en que quedó incorporada al Reino de Valencia ${ }^{42}$.

En 1777, el comerciante de origen irlandés José White y Vagué, vecino de Benicarló, efectuó una propuesta similar a la de Areny. Enriquecida con la exportación de vinos, la familia White adquirió tierras en el término de Ulldecona, efectuando importantes inversiones en plantíos ${ }^{43}$.

En marzo de 1778 el Consejo trasladó el memorial a los fiscales, quienes el 7 de abril dieron un dictamen muy positivo, pues la comarca donde se proyectaba la nueva población estaba despoblada y era de «grande importancia al Estado la fundación de nuevos lugares, siendo muy dignos de la Real Protección cuantos emprendiesen tales establecimientos». Como contrapartidas a su esfuerzo inversor, White demandaba se le hiciera gracia de los diezmos ${ }^{44}$, y a cambio de ello renunciaba a la jurisdicción suprema, aceptando tan sólo la alfonsina. White se comprometía a construir de su peculio entre 30 y 40 casas y, al igual que en la repoblación de Sierra Morena, solicitaba para sus colonos la concesión de exenciones fiscales y de levas y quintas durante una década.

Con posterioridad a 1772, la referencia al privilegio alfonsino también puede hallarse de forma explícita en proyectos de poblamiento en territorio aragonés, o de manera implícita en las Baleares. En el Fuero de 1329 se apoyó José Pérez Caballero, un labrador adinerado de Ainzón, en el corregimiento aragonés de Borja, para solicitar en 1784 la jurisdicción señorial en una nueva población que deseaba fundar en aquel término ${ }^{45}$. En su representación de 30 de septiembre de 1784 , por la que solicitaba licencia para fundar una nueva población de $\mathbf{2 0}$ casas, argüía precisamente que era la necesidad de brazos para continuar extendiendo los cultivos en el terreno acotado lo que le llevaba a solicitar el privilegio de población. Su única con-

42 Pujol Aguado (1994), p. 66.

43 A.H.N., Consejos, Libro 1.953, f. 79.

44 A.H.N., Consejos, leg. 37.141. Expediente a instancia de José White sobre la gracia del término que está sin dueño con los diezmos para la nueva población de Albi.

${ }^{45}$ A.H.N., Consejos, Libro 1.960, ff. 188-193v. 
dición era obtener, como compensación a su esfuerzo financiero, la jurisdicción ordinaria alfonsina.

La petición de jurisdicción como gracia por la fundación de una nueva población de al menos 15 casas fue utilizada también, aunque no de forma explícita, en el proyecto que en 1773 presentó el marqués de Sollarich, un vecino de Palma de Mallorca. Sollarich era poseedor de una cavallería denominada La Galera en el término de Felanitx ${ }^{46}$, y en virtud de ello solicitó «el uso de toda jurisdicción y señorio de vasallos» desde el momento en que construyera y ocupara con colonos 15 casas $^{47}$.

\subsection{El empleo del Fuero de Población de Sierra Morena}

El proceso repoblador de Sierra Morena sirvió de estímulo para nuevas realizaciones. Los intentos más tempranos tuvieron como objetivo la colonización de islas de evidente interés estratégico como Nueva Tabarca o San Pablo, frente a la costa de Alicante, y Cabrera.

En la primera de ellas, tradicional refugio de piratas y contrabandistas, tuvo lugar el asentamiento de 309 tabarquinos procedentes de la Tabarka existente frente a Túnez redimidos por frailes mercedarios en 1769 . El islote, de pequeñas dimensiones y absolutamente desierto hasta esa fecha, fue planificado urbanísticamente por ingenieros militares, que edificaron viviendas y las protegieron con murallas, y ocupado por sus nuevos pobladores en el año 1770. Establecer una población en un enclave tan poco grato sólo se justificaba por la estratégica situación de la isla, que cerraba por mar una plaza de armas de la importancia de Alicante.

Argumentos similares empleó en 1772 Tomás Villajuana, un letrado avecindado en Barcelona, cuando presentó una propuesta para poblar la isla de Cabrera ${ }^{48}$. Aparte del alivio que podía suponer conjurar la poca grata presencia en las calas de la isla de corsarios norteafricanos o de contrabandistas de tabaco mallorquines, la prevención de un posible ataque inglés desde Menorca no era un hecho a desdeñar; máxime si se tenía en cuenta la triste experiencia vivida dos años atrás en las islas Malvinas cuando una política excesivamente permisiva por parte española había permitido

46 El término cavallería en Mallorca hacía referencia a un territorio sujeto a dominio directo, cuyo titular, en origen, tenía la obligación de prestar servicio al rey con, al menos, un caballo armado. Sobre esta cuestión, véase Montaner (1986), pp. 42-65.

47 A.H.N., Consejos, Libro 1.944, f. 362v.

48 Alberola Romá y Giménez López (1994), pp. 85-92. 
el asentamiento de franceses e ingleses. Francia se retiró en 1766, pero a los ingleses hubo de expulsarlos una expedición organizada en 1770 por el capitán general de Buenos Aires ${ }^{49}$. El plan de Villajuana, pese a su aprobación por parte del Consejo de Castilla, mostró de inmediato su complejidad retrasándose su aplicación indefinidamente. Cuando Cabrera se convirtió en campo de concentración de prisioneros franceses durante la Guerra de la Independencia la isla mostró bien a las claras lo inadecuada que resultaba para un asentamiento humano ${ }^{50}$. La Tabarca alicantina, sin embargo y pese a las dificultades derivadas de un medio físico poco grato, ha mantenido su población hasta nuestros días, si bien en 1774 los nuevos pobladores protagonizaron un motín, reprimido por la guarnición militar, provocado por las durísimas condiciones de vida en la isla: «todos hemos pedido la misericordia de que presentase a S.M. por caridad nuestras miserias y el mísero lugar en el que no podemos vivir» ${ }^{51}$, decían en un memorial, fechado a principios de 1775 , dirigido al gobernador-corregidor de Alicante, conde de Baillencourt.

El poblamiento de lugares de interés estratégico era, como vemos, de interés prioritario para la administración. Cuando se proyectaba levantar una nueva población en terrenos próximos a las fronteras, la utilidad de la misma se veía incrementada notablemente a ojos de las autoridades. En 1769, un rico labrador de Garriguella, en la Girona septentrional, llamado Isidro Ferrán, solicitó licencia para fundar una nueva población, que se llamaría San Miguel de Colera, cerca de Port-Bou, lindante con el Mediterráneo y la frontera francesa, en un amplio terreno de su propiedad ${ }^{52}$.

Su proyecto consistía en ubicar 10 vecinos anuales durante cuatro años, hasta alcanzar la cifra de 40 vecinos, número que se consideraba idóneo para poner en cultivo toda la propiedad, en casas que serían cedidas a los colonos de forma gratuita durante el primer quinquenio. A cambio de todo ello Isidro Ferrán pedía ser ennoblecido.

El informe del capitán general de Cataluña fue muy favorable ${ }^{53}$. La mayor ventaja para el primer responsable político del Principado era la po-

49 Barcia (1943), Hidalgo (1947).

50 Roura i Aulinas (1985), pp. 150-158.

51 «... abbiamo tutti dimandato misericordia di apresentar ha sua Maestá per caritá le nostre miserie ed il misero luogo che non ci potiamo vivere», en A.G.S., Guerra Moderna, leg. 1.383. Representación del pueblo de Nueva Tabarca al Gobernador de Alicante conde de Baillencourt, Nueva Tabarca, 12 de enero de 1775.

52 A.H.N., Consejos, Libro 1.941, ff. 124v-135v.

53 El capitán general de Cataluña coincidía con el fervor poblacionista de los responsables políticos de la Corte: «es uno de los servicios que puede producir el amor de la Patria más 
sibilidad de reducir el contrabando haciendo «transitable y útil un desierto que no ba conocido otra planta que la del pastor, el contrabandista y las fieras». Tres años más tarde ya se habían construido 55 casas, formando el núcleo del pueblo, y otras 10 dispersas por el campo, todas habitadas por unos noventa colonos ${ }^{54}$.

Similar al proyecto de Ferrán fue el de José Masdevall. Al iniciarse la década de los noventa este conocido médico de la familia real ${ }^{55}$ presentó a la reina un proyecto para levantar a sus expensas una nueva población en unos terrenos de su propiedad en Biure d'Empordá, cerca de la frontera francesa, entre La Jonquera y Figueres. Por sus terrenos transcurría la carretera de Francia y tradicionalmente se efectuaban allí las entregas de las infantas reales que casaban con príncipes extranjeros. En homenaje a la reina María Luisa de Parma, a la que suplicaba fuera la protectora de la nueva población, y por el hecho referido, deseaba denominar a la nueva población «San Luis de las Reales Entregas».

Según Masdevall, dos eran las motivaciones que le impulsaban a realizar el proyecto. La nueva población podría acoger los séquitos que acompañaban a las infantas reales. Pero la segunda motivación era mucho más poderosa: la utilidad de levantar nuevas poblaciones en las proximidades de la frontera, «por ser ellas mismas unos perpetuos y vivos mojones que las conservaban y defendian ${ }^{56}$. Entre las pretensiones de Masdevall se encontraba, como más sustancial, la obtención de la jurisdicción baronal.

En ocasiones, el Fuero de Población de Sierra Morena era utilizado para maquillar importantes operaciones especuladoras, muy alejadas del espíritu inspirador de aquél. Sucede así con el proyecto de Narciso Comenge de crear una nueva población en los Monegros, en las inmediaciones de Sariñena, distribuyendo a cada colono una parcela de tierra de 53 fanegas. Al

grato y útil al aumento de la población y de la agricultura, siendo dos puntos tan principales de la felicidad del Estado. No hay dominio sin súbditos, ni puede haber subsistencia feliz sin la agricultura. Parecerá que no siendo otros los pobladores que los mismos que ya tiene la Provincia nada se gana en el primer objeto, pero es criar, o por mejor decir, es resucitar un vecino, ponerle en disposición con el establecimiento que asegura, de ser útil a la república para quien estaba muerto con indigencia, y en el como causa los demás efectos que contribuyen al fin», en A.H.N., Consejos, Libro 1.941, f. 129.

${ }_{44}$ A.H.N., Consejos, Libro 1.944, ff. 142v-147.

5S Sobre su perfil científico, ver Riera (1980). En noviembré Masdevall y al empleo de Méennoblecido: «En atención a los méritos y servicios de D. J Real Persona, he venido en concedico de Cámara con que se halla condecorado cerca de dientes», en A.G.S., Gracia y Justicia, Liderle privilegio de Nobleza, para si, sus hijos y descenbre de 1786.

bro 1.577 . Real Decreto en San Lorenzo, 3 de
st A.H.N., Consejos, Libro 1.966, f. $49 \mathrm{v}$. 
igual que los colonos de Sierra Morena, los nuevos pobladores estarian exentos durante una década del pago de impuestos reales. Para su trabajo y subsistencia, cada poblador recibiría dos bueyes y utensilios de labranza, ocho gallinas, un gallo y una cerda, y se le asignarían 30 árboles de la margen del río para que pudiera utilizar la leña de la poda. Pero estas disposiciones eran pura apariencia, pues el objetivo de Comenge era otro muy distinto.

La supuesta munificencia de Comenge debía ser recompensada con la concesión de la jurisdicción alta y baja, y el mero y mixto imperio; el derecho a percibir los diezmos y primicias; y la adjudicación a la nueva población, erigida en villa, de dos ferias anuales y mercado semanal, cuyos derechos le corresponderían, al igual que las regalías del horno, tienda y taberna.

Sin embargo el voluminoso informe redactado en noviembre de 1796 por la Audiencia de Aragón sobre los datos recopilados por el oidor Francisco Javier de La Ripa, comisionado por el tribunal para este menester, era muy contrario a las pretensiones de José Narciso Comenge ${ }^{57}$. La Ripa, trasladado a Sariñena, se informó con detalle, elaboró un minucioso mapa y llegó a la firme conclusión de que el proyecto era irrealizable y de nula utilidad. La extrema escasez de recursos hídricos en los Monegros, el coste desmesurado para poder canalizar agua hasta las tierras desde unos ríos de escaso caudal y sujetos a fuerte estiaje, y la reducida calidad de la tierra, hacían inviable la posibilidad de subsistencia de la nueva población. $\mathrm{El}$ informe de la Audiencia coincidía con el de su oidor comisionado. Los magistrados de la Audiencia tenían la certidumbre que la única finalidad de José Narciso Comenge era su enriquecimiento: todo el proyecto «era una figuración para vincularse en los seis montes otras tantas debesas de pastos y una pingüe renta» ${ }^{58}$, y el Consejo de Castilla, en su consulta de 25 de junio de $1798^{59}$, suspendió finalmente la licencia que pretendía el especulador.

\subsection{La colonización del Delta del Ebro}

El proyecto de colonizar el Delta —ese «juego de obstáculos» con que Pierre Vilar calificó el curso inferior del $\mathrm{Ebro}^{60}$ — resume en su ambicioso

37 A.H.N., Consejos, Leg. 6.123. Consulta del Consejo sobre los motivos de la Audiencia de Aragón para no evacuar el informe que se le pidió acerca de la gracia concedida a don José Narciso Comenge del Monte Mascallón, 18 de noviembre de 1796.

s8 A.H.N., Consejos, Libro 1.968 , f. 120.

59 A.H.N., Consejos, Libro 1.968, ff. 41-139v.

60 Vilar (1964), vol. I, p. 191. 
plan todos los elementos que hemos descrito hasta aquí: desecación de áreas pantanosas, iniciativa pública y privada y referencias explícitas y continuas tanto al Fuero de Población de Sierra Morena como al Fuero Alfonsino ${ }^{61}$.

En 1767, Carlos Sabater, un vecino de Tortosa ${ }^{62}$, proyectó construir dos canales a ambos márgenes del Ebro para salvar los obstáculos que impedían la navegación fluvial desde los puertos de El Fangar y los Alfaques, situados a ambos lados del Delta. Con ellos se evitaban las ciénagas y fondos irregulares de la desembocadura del río, y el salto llamado de la presa de Tortosa, utilizándose también para riego, además de «facilitar con la navegación el comercio maritimo al Reino de Aragón». El proyecto de Sabater también incluía el desagüe y desecación de zonas pantanosas y la construcción de diferentes pueblos en los terrenos bonificados. Sendos recursos al proyecto de Sabater presentados por el Cabildo eclesiástico de Tortosa y el Gremio de labradores de la misma ciudad lo dejaron momentáneamente en suspenso.

El 26 de julio de 1776 se remitió al Consejo de Castilla un memorial fechado el 8 de junio en el que los comerciantes de Barcelona Francisco Miláns y Benages, Francisco Canals, Andrés Filibein y Francisco Capalá, que se habían constituido en Compañía, se ofrecían hacer navegable y «poblar los términos desiertos que hay desde ella [Tortosa] basta el mar, al lado del río Ebro» ${ }^{63}$. Los Miláns formaban parte de la más activa clase mercantil catalana del Setecientos. Buenaventura Miláns había sido uno de los seis apoderados que firmaron en 1748 el proyecto de la Compañía de Comercio de Barcelona, y su primer director en 1755, junto a Bernat Gloria y Agustí Gibert ${ }^{64}$. Los Miláns y los Benages, de cuyo enlace familiar nacería Francisco Miláns y Benages, se habían especializado en seguros y préstamos, hasta llegar a constituir un banco de fondos en rentas vitalicias y dotes ${ }^{65}$.

61 Un estudio extenso de la colonización del Delta, en Giménez López (1995), vol. II pp. 41-66.

${ }_{62}$ En los años ochenta fue personero de Tortosa. En agosto de 1786, los comisarios electores de la ciudad solicitaron su prórroga en ese puesto. Vid. A.H.N., Consejos, leg. 37.152. Expediente a representación de los Comisarios Electores de la ciudad de Tortosa.

${ }^{63}$ A.H.N., Consejos, Libro 1.947, ff. 38-38v.

64 Oliva Melgar (1987), pp. 22-29.

65 Pierre Vilar (1964) hace una breve referencia a ello en la p. 472 del vol. IV de su Catalunya... Su potencial económico queda reflejado en el lugar que ocupó en el pago del catastro por el ganancial que ofrece Roberto Fernández en su estudio sobre la familia Gloria: en 1724 , Segismundo Miláns ocupó el tercer lugar; en 1762, el lugar ocupado por Buenaventura Miláns seguía siendo el tercero, mientras que en 1781, Francisco Miláns y Cía., ocupaba el cuarto lugar, pero pagando la misma cantidad que el tercero. En el cuadro correspondiente a todo lo que abonaron entre 1724 y 1752, la familia Miláns (Segismundo y Buenaventura) aparecen ubicados en el primer lugar con 32.032 rls. de ardite. Ver Fernández (1982), pp. 3-131. 
Poco después de la remisión al Consejo del memorial de Miláns y Compañía, Carlos Sabater solicitaba el 4 de agosto de 1776 se rechazase el propósito de aquéllos, por considerar que su proyecto era anterior y de mayor interés. Para garantizar la construcción y explotación de su proyecto, Sabater había constituido también una Compañía siguiendo un esquema similar al utilizado por Juan Agustín Badin y su hijo Luis Miguel para realizar el Canal Imperial de Aragón, que habían buscado financiación holandesa ${ }^{66}$. En el caso de Sabater, la obra se iba a financiar con capital procedente de Francia. A través de la compañía Fornier de Cádiz, con amplias relaciones comerciales con Europa ${ }^{67}$, se habían adherido a la empresa financieros de Lyon y Montpellier.

El proyecto de Carlos Sabater era más concreto y pormenorizado que el de Miláns y Compañía. Adjuntaba planos y una relación de 87 Condiciones que especificaban las obligaciones y contrapartidas que debían constituir el fundamento de la concesión por el monarca de la licencia para ejecutar las obras, y la retribución al capital invertido que debía provenir de toda una gama de privilegios, gracias y mercedes. Los fines del plan de 1767 se mantenían invariables: construir dos canales desde el azud de Tortosa hasta los puertos de El Fangar y Los Alfaques a ambos lados del Delta.

El objetivo del proyecto seguía siendo la bonificación de los terrenos pantanosos, convirtiéndolos en tierras regables de cultivo ${ }^{68}$, y facilitar la navegación hasta Tortosa. El plan de realizaciones expuesto por Sabater se completaba con la construcción a cuenta de su Compañía de 10 nuevas poblaciones, con 10.000 jornales cada una por término, sobre la base del Fuero de Población de Sierra Morena, pero una vez finalizadas las obras de canalización, según se especificaba en las condiciones, y cada pueblo contaría entre 20 y 30 casas. En el capítulo 71 de sus condiciones, Sabater ofrecía traer colonos extranjeros católicos, «por la suma falta de labradores en el distrito de Tortosa y la extensión del terreno» ${ }^{69}$.

${ }^{66}$ Pérez Sarrión (1984), pp. 59-68.

67 Chamboredon (1991), vol. II, pp. 35-53.

68 Condición 69. El proyecto de regadio se reducía a las dos grandes acequias; las hijuelas o acequias más pequeñas que debían conducir el agua de riego hasta las parcelas debían ser de cuenta de los propietarios, así como su conservación y limpieza. Pese a ello, en la condición 46 Sabater estaba dispuesto a asumir esos costos durante 10 años a cambio del pago de 8 rls. anuales por cada jornal de tierra. Ya que se estimaba posible el riego de unos 100.000 jornales, Sabater ingresaría por ese concepto unos 800.000 rls. al año, o 8 millones en una década, lo que venía a suponer la tercera parte de los gastos de la obra.

69 A.H.N., Consejos, Libro 1.946, f. 385 v. 
La información que ofrecía Miláns y Compañía era menos detallada ${ }^{70}$. En algunos puntos la similitud con el proyecto de Sabater es grande, y en lo fundamental eran idénticos, pues ambos trataban de construir dos canales que hicieran navegable el último tramo del Ebro, regar las tierras del Delta, desecar los pantanos y colonizar el territorio mediante la construcción de nuevas poblaciones. Las diferencias más sustanciales se encuentran en las condiciones y en las contrapartidas.

Como hemos señalado con anterioridad, Miláns ofrecía construir 20 nuevos pueblos, el doble de los proyectados por Sabater, pero en condiciones menos ventajosas para los colonos. Miláns rechazaba utilizar extranjeros, y se inclinaba por asentar colonos preferentemente catalanes, sin excluir a los procedentes de otros reinos de la Monarquía.

Pese a que el Consejo apoyó el proyecto de Sabater y Compañía, Floridablanca había decidido nombrar a Francisco Canals ${ }^{71}$, uno de los socios de la Compañía de Miláns, en calidad de su subdelegado y como comisario superintendente. El motivo de la intervención de Floridablanca en favor de la opción de Miláns hay que buscarlo en las vinculaciones de la Compañía de éste con el gobierno, como asentista de carnes saladas para la Marina, y en su participación en el comercio con Rusia, que Floridablanca deseaba impulsar, al tiempo que lo hacía también con Turquía y el Norte de África ${ }^{72}$.

El malestar del Consejo hacia la actuación resolutiva de Floridablanca fue evidente, pero Carlos III apoyó a su secretario de Estado ${ }^{73}$. El afán de éste por hacer progresar el proyecto mediante medidas expeditivas no logró que prosperase por las muchas dificultades que tenía una obra de tal complejidad, así como por la escasa capacidad de Canals, destituido en 1784, junto a su asesor José Riera y Alzamora ${ }^{74}$, tras la inspección a que fue so-

${ }^{70}$ Los fiscales solicitaron reiteradamente a Miláns y Cía. mayor especificación, Vid. A.H.N., Consejos, Libro 1.946, f. $377 \mathrm{v}$.

7 Sobre el nombramiento de Canals, ver referencia en Vilar (1966), vol. IV, p. 297, nota 175.

72 Pradells Nadal (1992), pp. 485-494.

73 A.H.N., Consejos, Libro 1.950 , f. 303.

${ }^{74}$ José Riera pretendió en 1787 una alcaldía, fiscalía del crimen en cualquiera de las Audiencias o el cargo de archivero en el Archivo de la Corona de Aragón para reparar los perjuicios que sufría desde que se le separó de la asesoría de las obras del canal de San Carlos: «Se va aumentando mi sentimiento e inquietud, y se redobla mi aflicción a proporción que se va difundiendo la separación de mi empleo, al mismo tiempo que considero que de todos mis servicios no tengo otro documento que el testimonio vivo de los que os han tocado y de V.E. con la aprobación de S.M. en el Reglamento general dispuesto por D. Vicente Carrasco y en las muchas y varias aprobaciones de las sentencias, providencias y dictámenes que en calidad de Asesor huve de dar sin haber experimentado la revocación de ninguna de ellas», en A.G.S., Gracia y Justicia, leg. 164. Memorial a José Riera y Alzamora, Barcelona, 14 de abril de 1787. 
metido por el intendente de Palencia, Vicente Carrasco, comisionado a tal efecto.

El nombramiento como nuevo comisionado de José Martorell, hasta entonces responsable de los trabajos a pie de obra, no supuso ningún avance significativo. Una epidemia de tercianas declarada en 1785 afectó la marcha de los trabajos ${ }^{75}$, y en 1786 el proyecto que quizá mejor había recapitulado todos aquellos mecanismos y experiencias utilizadas a lo largo del siglo XVIII para la colonización de despoblados quedó definitivamente paralizado.

\section{CONSIDERACIONES FINALES}

La colonización interior como medio de recuperación económica, al igual que otras facetas del reformismo borbónico, no se circunscribe al reinado de Carlos III. Sus raíces cabe buscarlas en los de Felipe V y Fernando VI, con especial énfasis en la desecación y repoblación de zonas pantanosas e insalubres. Sin embargo, el impulso colonizador recibe un empuje notable entre 1767 y 1772 . En ese sexenio el modelo repoblador de Sierra Morena, articulado en su Instrucción y Fuero de Población de julio de 1767, se convirtió en obligado marco de referencia para posteriores empresas colonizadoras. Como es sabido ${ }^{76}$, tres eran los principales objetivos que se perseguían con la operación repobladora encargada al superintendente Pablo de Olavide: su capacidad de ser imitada por individuos o grupos adinerados del resto del país tocados por el influjo de las luces, mantener la seguridad y el orden público y, por último, poblar zonas desiertas.

No obstante, en los antiguos territorios de la corona aragonesa, la Instrucción y Fuero de Población como instrumento de colonización se combinó con un mecanismo tradicional empleado por la nobleza desde las primeras décadas del siglo XIV para la repoblación de los territorios valencianos. Se trataba del Privilegio concedido por Alfonso IV en $1329 \mathrm{e}$ incorporado a los Fueros del reino más meridional de la Corona. Al igual que la Instrucción y Fuero de Población, el privilegio alfonsino estimulaba a la nobleza a la colonización interior ya que concedía la jurisdicción baronal, permitía el control del territorio y, en última instancia, favorecía la ocupa-

"Según Castella (1991, p. 341-352), las tercianas afectaron al propio Martorell y a su familia, falleciendo su mujer y su único hijo.

${ }^{76}$ Perdices Blas (1992), pp. 179-269. 
ción de áreas despobladas. Estuvo, por tanto, justificada su reposición en mayo de 1772 para que complementara al aludido Fuero de Población de Sierra Morena, así como que ambos instrumentos fueran invocados por particulares para las empresas colonizadoras que proyectaran. Lo llamativo del caso es que, si bien el privilegio alfonsino había quedado circunscrito a tierras valencianas desde el siglo XV hasta la abolición de los Fueros en 1707, después de su restablecimiento en 1772 fue utilizado también para solicitar, y en su caso obtener, la jurisdicción criminal baja y la civil plena en diferentes planes colonizadores diseñados para Baleares, Aragón y Cataluña.

Aun cuando el Fuero de Población fue esgrimido con frecuencia como modelo a seguir en los proyectos presentados ante el Consejo de Castilla, su propósito estuvo casi siempre destinado a disimular las auténticas motivaciones que movieron a los particulares que pretendían poner en práctica la colonización de territorios despoblados. En primer lugar la búsqueda de beneficios especulativos, que en ocasiones se centraban en la simple y llana explotación del trabajo de los colonos; en segundo lugar, el acceso inmediato al estamento privilegiado mediante el logro de la jurisdicción que otorgaba el privilegio alfonsino. Una vez más queda probado que individuos adinerados, muchos de ellos asimilables al concepto de burguesía, mostraban una decidida voluntad de crecer en riqueza, influencia y consideración en el contexto estamental del Antiguo Régimen.

\section{BIBLIOGRAFÍA}

AlBEROLA ROMA, Armando (1984): Jurisdicción y propiedad de la tierra en Alicante (siglos XVII y XVIII), Alicante.

- (1989): «La bonificación de enclaves insalubres en el País Valenciano durante la edad moderna. El ejemplo de la laguna de La Albufereta (Alicante)», en Investigaciones Geográficas, $\mathrm{n}^{\circ} 7$.

- (1993): «Los señoríos alfonsinos en el sur del País Valenciano. Aproximación a su estudio», en Señorío y feudalismo en la Península lbérica (ss. XII-XIX), Zaragoza, 4 vols.

- y GIMENEZ LOPEZ, Enrique (1994): «El proyecto de poblar la isla de Cabrera a fines del siglo XVIII», en Investigaciones Geográficas, $\mathrm{n}^{\circ} 12$.

ALTAMIRA Y CREVEA, Rafael (1905): Derecho consuetudinario y economía popular de la Álvrovincia de Alicante, Madrid.

pañol», en Armando Alberola y Emilio La Parra (eds.): La Ilustración Española. Actas del Coloquio Internacional celebrado en Alicante, 1985, Instituto de Estudios «Juan Gil-Albert», Alicante. 
AMAT, Lamberto (1875): Historia de Elda, manuscrito.

ARDIT LUCAS, Manuel (1977): Revolución liberal y revuelta campesina. Un ensayo sobre la desintegración del régimen feudal en el País Valenciano (1793-1840), Barcelona.

ARROYO IlerA, Rafael (1976): «La laguna de Salinas (Alicante) y su desecación», en Cuadernos de Geografía, n. ${ }^{\circ} 18$.

AvILÉs FERNÁNDEZ, Miguel (1991): «Historiografía sobre las Nuevas Poblaciones de Carlos III», en Miguel Avilés y Guillermo Sena (eds.): Nuevas Poblaciones en la España Moderna, Córdoba.

BARCIA, Camilo (1943): El problema de las islas Malvinas, Madrid.

BOX AMORÓs, Margarita (1987): Humedales y áreas lacustres de la provincia de Alicante, Alicante.

BRAUDEL, Fernand (1976): El Mediterráneo y el mundo mediterráneo en la época de Felipe II, Madrid (2." ed.), 2 vols.

CASTElla Beltrán, Josefa (1991): «San Carlos de la Rápita, otro proyecto de la Ilustración», en Miguel Avilés y Guillermo Sena (eds.): Nuevas Poblaciones en la España Moderna, Córdoba.

CAVANILLES, Antonio Josef (1795-1797): Observaciones sobre la historia natural, geografía, agricultura, población y frutos del Reyno de Valencia, Madrid, 2 vols.

CREMADES GriÑÁN, Carmen María (ed.) (1985): Estudios sobre el cardenal Belluga, Murcia.

(1991): «Los establecimientos de población de la Vega Baja del Segura en el siglo XVIII», en Miguel Avilés y Guillermo Sena (eds.): Nuevas Poblaciones en la España Moderna, Córdoba.

Chamboredon, Robert (1991): «Une Societé de Commerce Languedocienne a Cadix: Simón et Arnail Fornier et Cie. (Novembre 1768-Mars 1786)», en La burguesía de negocios en la Andalucia de la Ilustración, Cádiz, II vols.

DOMINGGEZ ORTIZ, Antonio (1976): Sociedad y Estado en el siglo XVIII español, Barcelona.

FERNANDEZ, Roberto (1982): «La burguesía barcelonesa en el siglo XVIII: la familia Gloria», en Pedro Tedde (ed.): La economia española al final del Antiguo Régimen; vol. II: Manufacturas, Madrid.

GaRCia MONERRIS, Carmen (1985): Rey y señor. Estudio de un realengo del País Valenciano (La Albufera, 1761-1836), Valencia.

GARCía MARTiNEZ, Sebastián (1964): «Evolución agraria de Villena hasta fines del siglo XIX», en Cuadernos de Geografía, n. ${ }^{\circ} 1$.

GARCIA SANZ, Ángel (1989): «La política agraria ilustrada y sus realizaciones», en Estructuras Agrarias y Reformismo Ilustrado en la España del siglo XVIII, Madrid, pp. 629-638.

GIL OLCINA, Antonio (1984): «La propiedad de la tierra en la laguna de Villena», en Investigaciones Geográficas, n. 2.

— y CANALES MARTÍNEZ, Gregorio (1988): Residuos de propiedad señorial en España, Alicante.

(1992): «Las políticas hidráulicas del reformismo ilustrado», en A. Gil Olcina y A. Morales Gil (eds.): Hitos históricos de los regadios españoles, Madrid. 
GIMÉNEZ LÓPEZ, Enrique (1993): «Fuero Alfonsino y Fuero de Población de Sierra Morena en los proyectos de colonización de la Corona de Aragón en la segunda mitad del siglo XVIII», en Revista de Historia Moderna, n. 12 (Alicante), pp. 141-184.

(1995): «La colonización del Delta del Ebro en la segunda mitad del siglo XVIII», en Homenaje al Dr. D. Antonio de Bethencourt Massieu, Las Palmas de Gran Canaria, 3 vols.

GOMEZ CRESPO, Juan (1968): «Un proyecto de colonización de los frailes cordobeses en Espiel», en Boletín de la Real Academia de Córdoba, n. ${ }^{\circ} 88$, pp. 237-250.

GOZÁlvez PÉREZ, Vicente (1977): El Bajo Vinalopó. Geografía agraria, Valencia.

Hernández Marco, José Luis (1983): Propiedad de la tierra y cambio social en un municipio fronterizo. Villena, 1750-1888, Alicante.

Hidalgo, Manuel (1947): La cuestión de las Malvinas, Madrid.

LEÓN CLOSA, Teresa (1962-1963): «Aportación al estudio de la colonización de la Vega Baja del Segura», en Anales de la Universidad de Murcia-Filosofia y Letras, volumen XXI (1962-1963).

Martín Rodríguez, Manuel (1984): Pensamiento económico español sobre la población, Madrid.

MARTÍNEZ DE LA MATA, Francisco: «Discurso segundo», en Gonzalo Anes (1971): Memoriales y Discursos de Francisco Martínez de la Mata, Madrid.

MATEU, Enric (1987): Arroz y paludismo. Riqueza y conflictos en la sociedad valen. ciana del siglo XVIII, Valencia.

Millán y GarCfa VARELA, Jesús (1984): Rentistas y campesinos. Desarrollo agrario y tradicionalismo político en el sur del País Valenciano (1640-1840), Alicante.

MONTANER, Pedro (1986): «Les cavalleries mallorquines (segles XIII-XVIII)», en Terra, treball $i$ propietat. Clases agraries $i$ règim senyorial als Països Catalans, Barcelona.

Morant Deusa, Isabel (1984): El declive del señorio. Los dominios del Ducado de Gandía (1705-1837), Valencia.

NADAL OLLER, Jordi (1976): La población española (siglos XVI a XX), Barcelona (4. a edición).

Oliva Melgar, Josep Maria (1987): Cataluña y el comercio privilegiado con América, Barcelona.

Perdices Blas, Luis (1992): Pablo de Olavide (1725-1803). El Ilustrado, Madrid.

PÉrez SARRIÓN, Guillermo (1984): Agua, agricultura y sociedad en el siglo XVIII. El Canal Imperial de Aragón (1766-1808), Zaragoza.

PeseT, M., y J. L. (1972a): «Cultivos de arroz y paludismo en la Valencia del siglo XVIII», en Hispania, n. ${ }^{\circ} 121$, pp. 277-375.

- (1972b): Muerte en España. Política y sociedad entre la peste y el cólera, 1972.

Pla Alberola, Primitivo (1993): «La jurisdicción alfonsina como aliciente para la recolonización del territorio», en Revista de Historia Moderna, $\mathrm{n} .{ }^{\circ} 12$.

PRADElls NADAL, Jesús (1992): Diplomacia y comercio. La expansión consular española en el siglo XVII, Alicante.

Pujol Aguado, José Antonio (1994): La Corona de Aragón en la Cámara de Castilla (1709-1721), Alicante.

RIERA, Juan (1980): José Masdevall y la medicina española ilustrada, Valladolid. 
Roura i Aulinas, Lluís (1985): L'Antic Règim a Mallorca abans de la conmoció dels anys 1808-1814, Barcelona.

RUIZ TORRES, Pedro (1981): Señores y propietarios. Cambio social en el sur del País Valenciano (1650-1850), Valencia.

SAAVEDRA FAJARDO, Diego de (1947): Idea de un Príncipe politico-cristiano, Madrid.

SAMBRICIO, Carlos (1991): Territorio y ciudad en la España de la Ilustración, Madrid. VILAR, Pierre (1964-1966): Catalunya dins l'Espanya Moderna, Barcelona, 4 vols.

VILAR, Jean (1973): Literatura y Economia. La figura satírica del arbitrista en el siglo de Oro, Madrid. 